\title{
Effect of glycine and glycine receptor antagonists on NMDA-induced brain injury
}

\author{
John E. Uckele ${ }^{1}$, John W. McDonald ${ }^{3}$, Michael V. Johnston ${ }^{4}$ and \\ Faye S. Silverstein ${ }^{1,2}$ \\ Departments of ${ }^{\prime}$ Pediatrics, ${ }^{2}$ Neurology, ${ }^{3}$ Neuroscience and Medical Scientist Training Program, University \\ of Michigan, Ann Arbor, MI (U.S.A.) and ${ }^{4}$ Johns Hopkins University School of Medicine and the Kennedy \\ Institute, Baltimore, MD (U.S.A.)
}

(Received 17 May 1989; Accepted 4 August 1989)

Key words: 7-Chlorokynurenic acid; Excitatory amino acid; Excitotoxicity; Glutamate; Glycine; Kynurenic acid; Neuroprotection; $N$-Methyl-D-aspartate

In postnatal day 7 rats, a unilateral intrastriatal injection of $12.5 \mathrm{nmol}$ of $N$-methyl-D-aspartate (NMDA) reproducibly injures the ipsilateral striatum, adjacent hippocampus and overlying cortex. The severity of injury can be quantified by comparing cerebral hemisphere weights in animals sacrificed 5 days after the injection. Co-injection of NMDA and the glycine receptor antagonists kynurenic acid (KYN) or 7-chlorokynurenic acid (7-CKA) reduced the severity of NMDA-induced damage in a dose-dependent fashion. One hundred nmol of KYN with $12.5 \mathrm{nmol}$ of NMDA reduced average $\%$ damage from $19.3 \pm 0.9 \%(n=9)$ to $2.3 \pm 0.5 \%(n=6), P<0.001$, ANOVA. Co-injection of $40 \mathrm{nmol}$ of 7-CKA with 12.5 nmol of NMDA $(n=6)$ reduced average \% damage from $17.1 \pm 1.6 \%(n=15)$ to $3.0 \pm 0.6 \%, P<0.001$, ANOVA. Concurrent injection of $1000 \mathrm{nmol}$ glycine with $5 \mathrm{nmol}$ NMDA did not increase the extent of NMDA-induced damage. Our results demonstrate that glycine receptor antagonists attenuate NMDAinduced brain injury in vivo.

The $N$-methyl-D-aspartate (NMDA) receptor/channel complex includes the NMDA-selective glutamate binding site, a cationic channel, and a strychnine-insensitive glycine receptor which is closely associated with the receptor/channel complex [1]. In vitro studies have demonstrated that glycine is required for NMDA receptor activation [12] and potentiates NMDA responses [3]. Kynurenic acid and 7-chlorokynurenic acid (7-CKA) are competitive antagonists of strychnine-insensitive $\left[{ }^{3} \mathrm{H}\right] \mathrm{gly}$ cine binding $[4,5]$.

Intrastriatal injection of NMDA in postnatal day (PND) 7 rats produces reproducible damage to the ipsilateral striatum, adjacent hippocampus, and the overlying cortex [8]. The severity of brain injury can be quantified by comparing the weights of

Correspondence: F.S. Silverstein, Neuroscience, Laboratory Building, 1103 E. Huron Street, Ann Arbor, MI 48104-1687, U.S.A. 
the injected and contralateral cerebral hemispheres in animals sacrificed 5 days later, on PND $12[9,10]$. In this study, we examined the ability of glycine receptor agonists and antagonists to potentiate or attenuate NMDA-induced brain injury in the immature brain. To ensure consistent drug delivery, all drugs were administered by direct intra-cerebral injection.

Seven-day-old Sprague-Dawley albino rats were anesthetized with diethyl ether. Stereotaxic injections of NMDA in $0.5 \mu \mathrm{l}$ phosphate-buffered saline (PBS) were made in the right striatum of each rat pup (co-ordinates referenced to bregma: AP $2 \mathrm{~mm}$, ML $2.5 \mathrm{~mm}$, V $4 \mathrm{~mm}$ ). In the first experiment, pups received $5 \mathrm{nmol} \mathrm{NMDA}$, with or without co-injection of $1000 \mathrm{nmol}$ glycine. The next group of experiments included equal numbers of pups that received $12.5 \mathrm{nmol}$ NMDA with or without co-injection of kynurenic acid ( 4 doses, $12.5-100 \mathrm{nmol}$ ) or 7-CKA ( 4 doses, $2.5-40 \mathrm{nmol}$ ). After recovery from anesthesia, the pups were returned to the dam. Animals were sacrificed by decapitation on postnatal day 12,5 days after lesioning.

The severity of brain injury was quantified by deriving a \% damage value, calculated as the difference between the contralateral hemisphere $(C)$ weight and the injected $(I)$ hemisphere weight, divided by the contralateral hemisphere weight (\% damage $=C-I / C \times 100)$. Previous studies indicate that in this experimental model, the $\%$ damage value is a consistent measure of the severity of neuronal injury and the efficacy of neuroprotective agents [9]. At doses of NMDA ranging from 5 to 25 $\mathrm{nmol}$, there is a direct linear correlation between \% damage and progressive reductions in both choline acetyltransferase activity and striatal cross-sectional area [10]. Data was expressed as average \% damage \pm S.E.M. in all groups. At $12.5 \mathrm{nmol}$ NMDA $(n=24)$ produced an average \% damage of $18.1 \pm 1.2 \%$. Brain injury was also evaluated by histologic examination of Nissl-stained coronal brain sections.

The doses of drug that reduced damage by 505 (protective dose $50, \mathrm{PD}_{50}$ ) were determined by the method of Litchfield and Wilcoxon [6]. Statistical comparisons were made by analysis of variance (ANOVA).

To examine the issue of potentiation of NMDA-induced injury by glycine, we used the lowest dose of NMDA, $5 \mathrm{nmol}$, that elicited a reproducible lesion. Injection of $1000 \mathrm{nmol}$ of glycine with $5 \mathrm{nmol}$ NMDA did not increase NMDA-induced brain injury when compared to controls which received $5 \mathrm{nmol} \mathrm{NMDA}$ alone. Average \% damage for experimentals $(n=6)$ was $9.3 \pm 1.2 \%$, compared with $10.5 \pm 1.2 \%$ for controls $(n=6), P=$ N.S., by ANOVA.

In contrast, co-injection of increasing doses of the glycine receptor antagonist kynurenic acid (KYN) with 12.5 nmol NMDA progressively reduced the extent of NMDA-induced brain injury. Four doses of KYN were evaluated: $12.5 \mathrm{nmol}(n=6)$, $25 \mathrm{nmol}(n=6), 50 \mathrm{nmol}(n=8)$ and $100 \mathrm{nmol}(n=5)$. At each dose, the extent of NMDA-induced brain injury was reduced, $P<0.001$, ANOVA (Fig. 1A); $\%$ damage in brains injected with $100 \mathrm{nmol} \mathrm{KYN}$ fell to $2.3 \pm 0.5 \%$. The $\mathrm{PD}_{50}$ for $\mathrm{KYN}$ was 34.1 nmol. In addition, histologic sections confirmed a marked reduction in injury to the ipsilateral striatum, hippocampus and cortex in animals injected with $100 \mathrm{nmol} \mathrm{KYN}$ and $12.5 \mathrm{nmol}$ NMDA (Fig. 2B) when compared to controls injected with $12.5 \mathrm{nmol}$ NMDA only (Fig. 2A). 

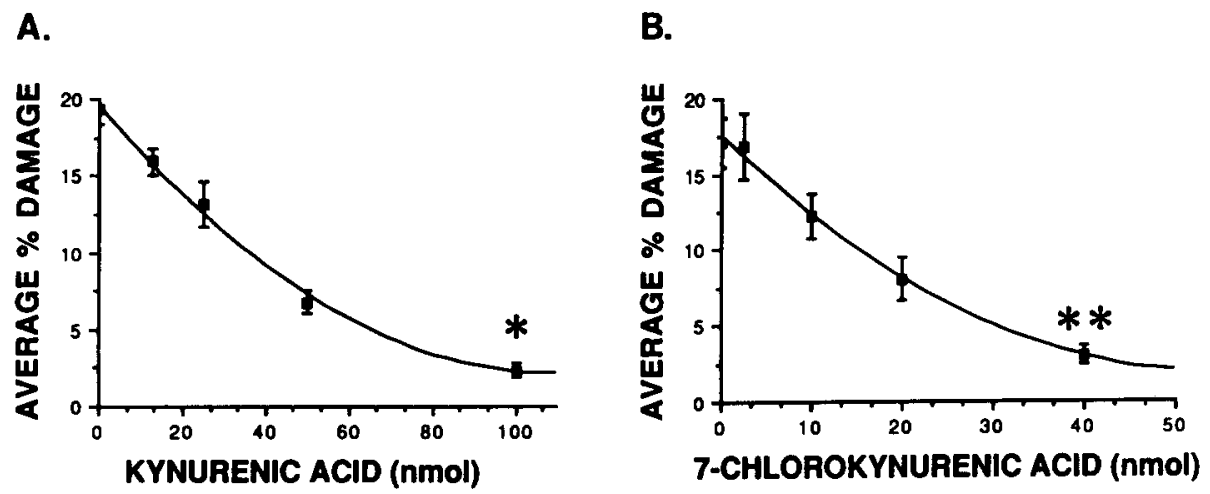

Fig. 1. Dose-response curves showing average \% damage vs dose of kynurenic (KYN) acid (A) and 7-chlorokynurenic acid (7-CKA) (B) with concurrent administration of $12.5 \mathrm{nmol} \mathrm{N}$-methyl-D-aspartate (NMDA). Postnatal day (PND) 7 rats received right intrastriatal injection of 12.5 nmol NMDA with KYN (dose range: $0-100 \mathrm{nmol}$ ) or 7-CKA (dose range: $0.40 \mathrm{nmol}$ ). Animals were sacrificed on PND 12. $\%$ damage was calculated by comparison of the injected $(I)$ and contralateral $(C)$ hemisphere weights $(C-1 / C \times 100)$ for each group and expressed as mean \pm S.E.M. ${ }^{*} P<0.001$, compared with $12.5 \mathrm{nmol}$ NMDA-injected controls, ANOVA, post-hoc $t$-test indicated significant differences at each dose: ${ }^{* *} P<0.001$, compared with $12.5 \mathrm{nmol}$ NMDA-injected controls, ANOVA, post-hoc $t$-tests indicated significant differences at doses 10,20 and $40 \mathrm{nmol} 7$-CKA.

The neuroprotective effects of 7-CKA on NMDA-induced brain injury were similar. Doses of 7-CKA including $2.5 \mathrm{nmol}(n=9), 10 \mathrm{nmol}(n=6), 20 \mathrm{nmol}(n=6)$ and $40 \mathrm{nmol}(n=6)$ were co-injected with $12.5 \mathrm{nmol}$ NMDA. The lowest dose tested, 2.5 nmol 7-CKA, did not reduce injury. Doses of 10, 20, and $40 \mathrm{nmol} 7$-CKA progressively reduced the severity of NMDA-induced brain injury, $P<0.001$, ANOVA (Fig. 1B). The $\mathrm{PD}_{50}$ of 7-CKA calculated from these data was $17.6 \mathrm{nmol}$. Higher doses of 7-CKA could not be tested because of limitations in solubility of the drug. Coronal sections of brains injected with 40 nmol 7-CKA and 12.5 nmol NMDA (Fig. 2C) demonstrated relative preservation of histologic integrity of the striatum, hippocampus and cortex as compared to controls injected with $12.5 \mathrm{nmol}$ NMDA only (Fig. 2A).

KYN has mixed glutamate antagonist properties, inhibiting $\left[{ }^{3} \mathrm{H}\right] \mathrm{glycine}$ binding in a competitive manner and also inhibiting $\left[{ }^{3} \mathrm{H}\right]$ glutamate binding to NMDA receptors [2]. However, 7-CKA has 70-80 times the specificity of kynurenic acid for the strychnine-insensitive glycine site [4]. The increased efficacy (lower $\mathrm{PD}_{50}$ ) observed of 7-CKA over KYN may be attributable to increased specificity of 7-CKA at the glycine modulatory site. These results are consistent with a recent report [11] which demonstrated that 7-CKA blocked glutamate neurotoxicity in cell culture and that glycine could reverse its neuroprotective effects.

These data demonstrate that glycine receptor antagonists can attenuate NMDAinduced neurotoxicity in vivo. The inability of exogenous glycine to potentiate NMDA-induced brain injury may be due to maximal receptor occupation by physiologic concentrations of glycine in vivo. Drugs which act as glycine receptor antago- 


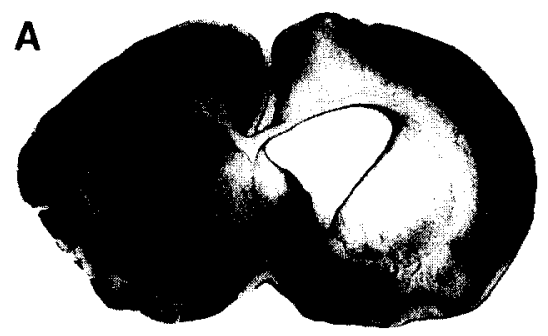

NMDA

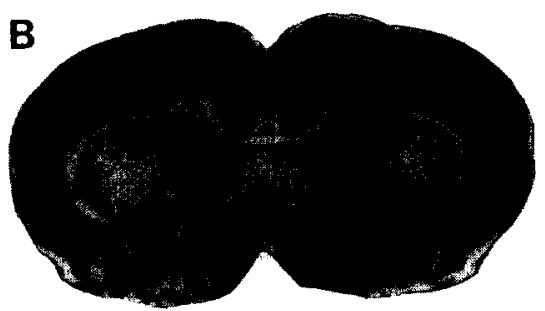

NMDA \& KYN

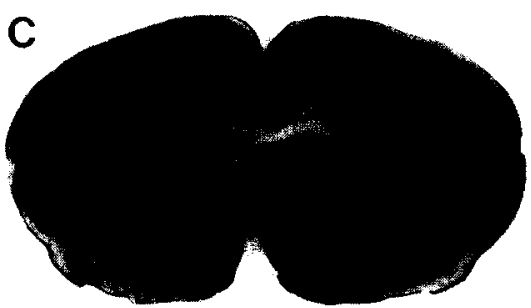

NMDA \& 7-CKA

$\overline{i m m}$

Fig. 2. Representative Nissl-stained coronal brain section $(75 \mu \mathrm{m})$ from rat pups sacrificed at postnatal (PND) day 12. On PND 7, ether anesthetized rats received right intrastriatal injections of $12.5 \mathrm{nmol}$ NMDA (A), $12.5 \mathrm{nmol}$ NMDA and $100 \mathrm{nmol} \mathrm{KYN} \mathrm{(B),} \mathrm{and} 12.5 \mathrm{nmol}$ NMDA and $40 \mathrm{nmol} 7$-CKA (C). The severity of injury is markedly reduced by both KYN acid and 7-CKA.

nists may have neuroprotective properties in neurologic disorders associated with over-activation of NMDA receptors.

\section{Supported by NS 01171 and 26142 (F.S.S.).}

I Bristow, D.R.. Bowery, N.G. and Woodruff. G.N., Light microscopic autoradiographic localisation of [ $\left.{ }^{3} \mathrm{H}\right]$ Glycine and [ $\left.{ }^{3} \mathrm{H}\right]$ Strychnine binding sites in rat brain, Eur. J. Pharmacol., 126 (1986) 303-307.

2 Danysz, W., Fadda, E., Wroblewski, J.T. and Costa, E., Kynurenate and 2-amino-5-phosphonovalerate interact with multiple binding sites of the $\mathrm{N}$-methyl-D-aspartate-sensitive glutamate receptor domain. Neurosci. Lett., 96 (1989) 340-344.

3 Johnson, J.W. and Ascher, P.. Glycine potentiates the NMDA response in cultured mouse brain neu- 
rons, Nature (Lond.), 325 (1987) 529-531.

4 Kemp, J.A., Foster, A.C., Leeson, P.D., Priestley, T., Tridgett, R. and Iversen, L.L., 7-Chlorokynurenic acid is a selective antagonist at the glycine modulatory site of the $\mathrm{N}$-methyl-D-aspartate receptor complex, Proc. Natl. Acad. Sci., U.S.A., 85 (1988) 6547-6553.

5 Kessler, M., Baudry, M., Terramani, T. and Lynch, G., Complex interaction between a glycine binding site and NMDA receptors, Soc. Neurosci. Abstr., 13 (1987) 760.

6 Litchfield, J.T. and Wilcoxon, F., A simplified method of evaluating dose-effect experiments, J. Pharmacol. Exp. Ther., 96 (1949) 99-113.

7 Mayer, M.L., Vyklicky, Jr. L., and Clements, J., Regulation of NMDA receptor desensitization in mouse hippocampal neurons by glycine, Nature (Lond.), 338 (1989) $425-427$.

8 McDonald, J.W., Silverstein, F.S. and Johnston, M.V., Neuroprotective effects of MK-801, TCP, PCP and CPP against $N$-methyl-D-aspartate induced neurotoxicity in an in vivo perimatal rat model, Brain Res., 490 (1989) 33-40.

9 McDonald, J.W., Silverstein, F.S., Cardona, D., Hudson, C., Chen, R. and Johnston, M.V., Systemic administration of MK-801 protects against $N$-methyl-D-aspartate and quisqualate mediated neurotoxicity in perinatal rats, Neuroscience, in press.

10 McDonald, J.W., Roeser, N.F., Silverstein, F.S. and Johnston, M.V., Quantitative assessment of neuroprotection against NMDA-induced brain injury, Exp. Neurol., in press.

11 Shalaby, I., Chenard, B. and Prochniak, M., Glycine reverses 7-Cl kynurenate blockade of glutamate neurotoxicity in cell culture, Eur J. Pharmacol., 160 (1989) 309-311.

12 Thomson, A.M., Walker, V.E. and Flynn, D.M., Glycine enhances NMDA-receptor mediated synaptic potentials in neocortical slices, Nature (Lond.), 338 (1989) 422-424. 